\title{
Another Step in the Modeling of Basque Intonation: Bermeo
}

\author{
Gorka Elordieta ${ }^{1}$, Iñaki Gaminde ${ }^{2}$, Inma Hernáez, Jasone Salaberria, and \\ Igor Martin de Vidales ${ }^{2}$ \\ ${ }^{1}$ Dpto. Filología Inglesa, E.U.I.T.I. e I.T.T., Universidad del País Vasco, Nieves Cano 12, \\ 01006 Vitoria-Gasteiz, Spain \\ fipelalg@vc.ehu.es \\ ${ }^{2}$ Dpto. Hizkuntza eta Literaturaren Didaktika Saila, Irakaslegoaren Unibertsitate Eskola, \\ Euskal Herriko Unibertsitatea, Ramón y Cajal 72, 48014, Bilbo, Spain \\ tlpgatei@lg.ehu.es
}

\begin{abstract}
In this paper the basic features of the intonational structure of Bermeo Basque (BB) are analyzed. In BB there exists a lexical distinction between accented and unaccented words. Accented words are always stressed, and unaccented words (not containing any accented morphemes) only receive stress on their final syllable when they are immediately preceding the verb; otherwise they surface stressless. BB shows a hierarchically organized intonational structure. Accentual Phrases are identified by an initial \%L boundary tone, a phrasal $\mathrm{H}$ - tone associated to the second syllable, and a nuclear $\mathrm{H}^{*}$ pitch accent. $\mathrm{H}$ - spreads rightwards to other syllables until a $\mathrm{H}^{*}$ pitch accent is met. A $\mathrm{H}^{*}$ pitch accent triggers downstep on the following $\mathrm{H}^{*}$. An Intermediate Phrase contains one or more APs, and is the domain of downstep. Finally, an Intonational Phrase is signalled by a final $\mathrm{L} \%$ in declarative
\end{abstract}

\section{Introduction}

In this paper we provide an analysis of the intonational structure of a dialectal variety of Basque spoken in Bermeo, on the coast of Bizkaia (the westernmost Basque dialect). The importance of this study lies on the fact that it constitutes another step towards modeling the intonation of Basque, a language about whose intonation very little is known so far. Basque is substantially fragmented into several dialects and local varieties within each of them. There are seven dialects, according to modern commonly-accepted assumptions, and approximately fifty dialectal varieties, according to some authors. The standard dialect cannot be studied, because there is no commonly agreed-on prosody in this dialect (the Academy of the Basque language has not provided any rules or guidelines in this domain). Therefore, in order to know what the main properties of Basque intonation are, one must study as many varieties as possible. Only after a comparison of the intonational characteristics of the different dialects will it be possible to establish the general features that are common to all or most of the dialects, as well as the main differences among them. In the end, if as it is our hope the differences are not very dramatic, it will be possible to offer a model of 
Basque intonation. Such a model will have advantages both for the completion of the standardization process of the language and for technological applications. In the latter domain, our goal is to implement the model we obtain on a speech synthesizer for Basque.

In section 1, we present the basic features of the accentual system of Bermeo Basque. Section 2 describes the methodological aspect of the work. The results of our analysis are discussed in section 3. Finally, section 5 contains some concluding remarks.

\section{Accentual System}

Like all dialects spoken in Northern Bizkaia, the dialect of Bermeo is a pitch accent dialect, which could be classified into the accentual variety known as Getxo-Gernika. Previous work on the accentual system of Bermeo [3,4] shows that pitch is lexically distinctive in this variety, as words can be lexically distinguished between being accented or unaccented. Lexically accented words are those that contain one or more accented morphemes, and display stress on the syllable which precedes the syllable that contains the accented morpheme. Affixes of the plural nominal declension are accented, as well as some affixes in the singular as well [3]. Some roots may be accented as well [4]. Lexically unaccented words, on the other hand, are those that do not contain any accented morphemes and only receive word-level stress when they occur in immediate preverbal position. In this type of contexts, stress falls on the last syllable of the word. In all other positions, unaccented words do not display stress. Thus, the lexically unaccented word laguné '(the) friend' occurs immediately to the left of the verb in (3), and receives stress on its final syllable. In (4), however, this word does not occur adjacent to the left of the verb, and therefore it does not receive stress. Unlike lexically unaccented words, lexically accented words always display surface stress, irrespective of their position in the sentence.

1. gi.xó.nak (gixon 'man' + accented affix $-a k$ 'determiner plural') mu.ti.llé.gas (mutil 'boy' + - a 'det.sg.' + accented affix -gas 'comitative')

2. lé.ku 'place' a.mú.ma 'granny'

3. laguné etorri da 'the friend has come' friend come aux

4. lagune gixonágas etorri da 'the friend has come with the man' friend man-with come aux

\section{Methodology}

With these properties in mind, for this pilot study we recorded 365 utterances from a female speaker of the dialect of Bermeo, with different word orders and numbers of phrases. Thus, the utterances could be of the following kind: a) containing one phrase of two or three syllables, before and after the verb; b) containing two phrases of two or three syllables, before and after the verb; and c) containing three phrases of two or 
three syllables, before and after the verb. The speaker had to read the utterances as naturally as possible. The recordings were made in a quiet room, with the use of a monodirectional microphone and a digital recorder. The data were analyzed by measuring F0 values for every syllable.

\section{Experimental results}

The dialect of Bermeo presents a very similar intonational structure to that of the dialect of Lekeitio, previously described and analyzed in [2,6,7]. Couching our analysis within the framework known as the ToBI model of intonation analysis $[1,8,9,10]$, we identified three intonational constituents: the Accentual Phrase (AP), the Intermediate Phrase (iP) and the Intonation Phrase (IP). All three constituents presented the same tonal/intonational cues as in Lekeitio.

An Accentual Phrase (AP) can be identified by three tonal cues. Its left edge is marked by a $\% \mathrm{~L}$ boundary tone which associates to the first syllable of the AP. Then, a phrasal $\mathrm{H}$ - is phonologically associated to the second syllable of the AP, and is usually phonetically realized on the second syllable. This tone spreads phonetically until the third tonal cue of an AP is met: the $\mathrm{H}^{*}$ pitch accent, phonologically associated to the accented syllable, whether underlying (i.e., of an accented word) or derived (i.e., of a lexically unaccented word which occurs in immediate preverbal position). This pattern is illustrated in Fig. 1 which shows the F0 curve corresponding to the sentence "gixonak óllarra saldu dau" (the man has sold the rooster). After the high tone on the accented syllable there is a steep fall in pitch on the following syllable. The $\mathrm{H}^{*}$ pitch accent marks the last word of the AP. That is, if after a $\mathrm{H}^{*}$ accent there is another word in the utterance, it will display the same tonal pattern: $\% \mathrm{~L}$ on the first syllable, $\mathrm{H}-$ on the second syllable, and $\mathrm{H}^{*}$ on the accented word.

As for issues of relative prominence among high tone peaks, it should be pointed out that as in Lekeitio, the accent in the word immediately preceding the verb is the most prominent in the utterance. After the preverbal word, the pitch level is reduced, and therefore all following accents present reduced peaks in the F0 curve. Another phenomenon affecting relations of prominence that can be observed in Bermeo Basque is downstep; a $\mathrm{H}^{*}$ accent, derived or underived, causes downstep on a following $\mathrm{H}^{*}$ within the same syntactic phrase. Thus, the presence of two or more APs in a syntactic phrase, each with its own $\mathrm{H}^{*}$, may give rise to a ladder-type configuration, as shown in Fig. 2, corresponding to "mallúkidxe lagunek jan dau" (the friend has eaten the strawberry).

An Intermediate Phrase (iP) has no tonal cues, but can be identified by the blocking of downstep. The left edge of an iP corresponds to the left edge of an AP that is the initial AP in a syntactic phrase. An iP may contain one or more APs, and is thus the domain of downstep.

An Intonational Phrase (IP) is signaled by L\% boundary tones on the right edge of declarative utterances, and $\mathrm{H} \%$ for list-type sentences and interrogative utterances. Another property that marks the right edge of an IP is lengthening of the final vowel. 


\section{Conclusions}

To conclude, the model of intonation of Bermeo Basque (mid-northern Bizkaian) provided in this study presents striking similarities with the one of Lekeitio, a northwestern Bizkaian variety [2,7]. [5] reports similar intonational properties for the northeastern Bizkaian dialect of Gatika. This indicates that there is a common intonational structure for northern Bizkaian. This finding constitutes an important step towards the bigger goal of achieving a unified model of Basque intonation. Our next objective is to investigate the intonation of other dialects.

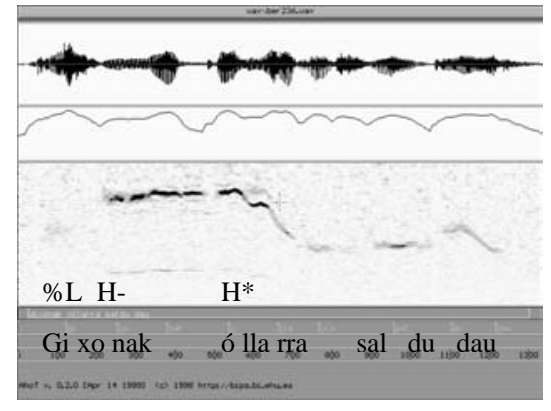

Fig. 1. Spreading of a H- up to $\mathrm{H}^{*}$

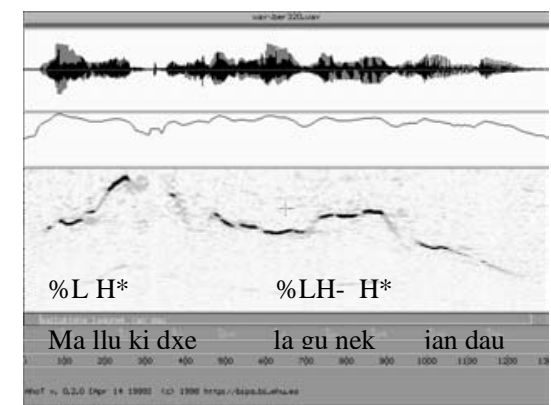

Fig. 2. Ladder-type configuration

\section{References}

1 Beckman, M.; and Ayers, G.: Guidelines for ToBI labelling, Ms., Ohio State University. (1994)

2 Elordieta, G.: Accent, tone and intonation in Lekeitio Basque. In: Martínez-Gil F., Morales A..(eds.): Issues in the Phonology and Morphology of the Major Iberian Languages., Washington, D.C.: Georgetown University Press. (1997) pp. 3-78.

3 Gaminde, I.: Bermeoko Azentu-Ereduaz. Uztaro 8, (1993) pp 105-117 (in Basque)

4 Gaminde, I.: Bizkaieraren Azentu-Moldeez. Labayru, (1995) Bilbo (in Basque)

5 Gaminde, I.: Gatikako Euskaraz. Gogoz Euskara Taldea, (1997) Gatika (in Basque)

6 Hualde, J.I.; Elordieta, G. and Elordieta, A.: The Basque Dialect of Lekeitio. Supplements of ASJU. UPV y Diputación Foral de Gipuzkoa. (1994)

7 Jun, Sun-Ah, Elordieta G.: Intonational structure of Lekeitio Basque. In: A. Botinis, G. Kouroupetroglou and G. Carayiannis (eds.): Intonation: Theory, Models and Applications. Proc. ESCA Workshop, (1997) pp. 193-196.

8 Pierrehumbert, J.: The Phonetics and Phonology of English Intonation. MIT doctoral dissertation. (1980)

9 Pierrehumbert, J.; Beckman, M.: Japanese Tone Structure. Cambridge, Mass.: MIT Press. (1988)

10 Silverman, K.; Beckman, M.; Pitrelli, J.; Ostendorf, M.; Wightman, C.; Price, P.; Pierrehumbert, J.; and Hirschberg, J.; ToBI: a standard for labeling English prosody. Proc. $2^{\text {nd }}$.Int. Conference on Spoken Language Processing, Vol 2 Banff, Canada. (1992) pp. 867870 . 